\title{
浅谈加强土木工程结构设计安全性的措施讨论
}

\author{
张庚彪* \\ 山东东瑞规划建筑设计院有限公司, 山东 274300
}

\begin{abstract}
摘 要: 随着国民经济的不断提高, 土木工程建设设计行业也在迅速发展进步。建筑结构设计的安全性, 直接影 响建筑工程质量, 关系到人们生命与财产的安全。随着生活水平的提高, 人们对建筑安全性的要求不断提高, 提高建 筑结构设计的安全性成为评价设计水平的重要标准。本文主要阐述评价建筑结构设计安全性原则, 分析我国建筑结构 设计中常见的安全问题，并提出了增强建筑结构设计安全性的建议，以供相关实践研究参考借鉴。
\end{abstract}

关键词：土木工程; 结构设计; 安全性; 改进措施

\section{Discussion on Measures to Strengthen the Safety of Civil Engineering Structure Design}

\author{
Geng-Biao Zhang*
}

Shandong Architectural Planning and Design Institute Limited Dawnray, Heze 274300, Shandong, China

\begin{abstract}
With the continuous improvement of the national economy, the civil engineering construction design industry is also developing rapidly. The safety of building structure design directly affects the quality of construction engineering and the safety of people's life and property. With the improvement of living standards, people's requirements for building safety continue to improve. Improving the safety of building structure design has become an important standard to evaluate the design level. This paper mainly expounds the principles of evaluating the safety of building structure design, analyzes the common safety problems in China's building structure design, and puts forward some suggestions to enhance the safety of building structure design, so as to provide reference for relevant practical research.
\end{abstract}

Keywords: Civil engineering; Structural design; Safety; Improving measures

\section{一、引言}

我国建筑规模呈现更高更大的发展趋势, 工程复杂性不断提高, 对安全性的要求也在不断提高 ${ }^{[1]}$ 。如何保障建筑 结构的安全性, 已经不仅是建筑行业关注的问题, 还引起社会各界的广泛关注。保障建筑使用安全的关键在于建筑结 构设计的安全性, 提高建筑结构设计的安全性, 不仅是人们对建筑质量的评价基础, 同时也是建筑行业自身在追求的 目标, 对其的研究具有十分重要的意义。

\section{二、土木工程结构安全性概述}

土木工程结构的安全性是指建筑物可以承受规定的重量, 可以适应风、雨、雪等天气，在台风、地震和火灾极端 情况下不崩塌, 能够维持建筑结构稳定的特性, 受到施工设计、施工质量与后续维护等影响 ${ }^{[2]}$ 。在进行建筑结构设计 时, 应该根据结构损坏后果的严重性确定建筑结构安全等级 (如表1所示), 需要注意的是, 特殊建筑物的安全等级 需要根据情况另行判断。

表1 建筑结构安全等级

\begin{tabular}{|c|c|c|}
\hline 安全等级 & 结构损坏后果 & 建筑类型 \\
\hline 一级 & 非常严重 & 重要建筑 \\
\hline
\end{tabular}

*通讯作者: 张庚彪, 1988年11月, 男, 汉族, 山东菏泽人, 就职于山东东瑞规划建筑设计院有限公司, 中级工 程师, 硕士研究生。研究方向: 结构设计。 
续表:

\begin{tabular}{|c|c|c|}
\hline 安全等级 & 结构损坏后果 & 建筑类型 \\
\hline 二级 & 严重 & 一般建筑 \\
\hline 三级 & 不严重 & 次要建筑 \\
\hline
\end{tabular}

三、土木工程结构设计安全性原则

（一）结构设计整体性原则

建筑各层的重力通过楼板传递至地面, 当楼板受力不均时, 需要通过梁结构约束承重柱等结构, 增强其刚度, 以 确保结构承受外力时不变形。结构设计需要依照各部分构件的承重能力进行分配。

建筑结构的总体布置的提高设计安全性的关键。建筑的结构单元平面规划应该尽量规则简单, 避免复杂结构的影 ${ }^{n^{6}}{ }^{[3]}$; 建筑立面设计应该避免伸缩, 避免建筑重心偏移; 建筑内部结构应该尽量对称, 分布均匀。科学的整体结构可 以迅速传递并消耗建筑受到的外力, 保障建筑安全。在建筑的设计阶段, 应该以建筑结构整体性的安全为基础, 考虑 各个建筑构件的设计与使用, 确保建筑构件设计遵循是围绕建筑整体的安全性展开。另外, 在建筑结构设计过程中, 不仅要分析解结构力学, 还要分析建筑构件之间的关系。

\section{（二）结构弹塑性适度原则}

所谓 “刚过易折” , 建筑结构的设计需要考虑留有适宜的弹性。如果建筑的刚度过高, 在受外力影响时不能变形 释放能量, 反而会导致能量迅速聚集, 到达建筑承受极限后, 能量释放将会造成更大的损害。如果建筑保留过高的弹 性, 建筑的结构稳定性会过低, 导致建筑容易变形, 变形程度过高, 会引发更大的安全问题。所以, 建筑结构设计需 要保留适度的弹性, 过高过低都不可取 ${ }^{[4]}$ 。

在极端灾害中, 地震对建筑的破坏最为显著, 建筑结构的弹性适度原则主要也是针对地震而言。在地震中, 地面 加速度的实际情况会远高于设计预期的加速度, 需要依靠建筑结构的塑性状态降低地震对建筑结构的损害, 这个过程 需要保证结构有充足的延性, 能大量吸收地震释放的能量 ${ }^{[5]}$ 。延性相对的是脆性, 延性破坏相对于脆性破坏能吸收更 多能量 (如图1所示), 能够有效提高建筑结构安全性。因此, 在建筑结构的设计阶段就要防止结构刚性破坏, 达到 抗震设计的要求, 设计要求为小震结构弹性吸收; 中震结构损坏可维修; 大震结构损坏不坍塌。

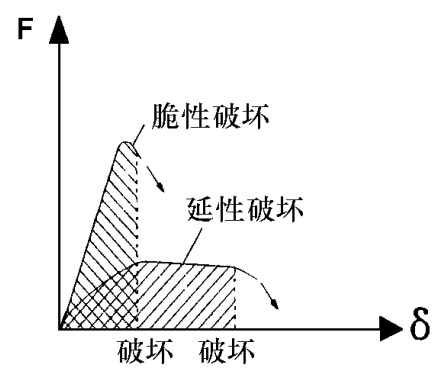

图1 荷载一变形曲线

\section{(三) 多重防护原则}

建筑结构的安全性不能依靠一层防护措施, 所以建筑结构设计的安全性需要遵循多重防护原则。多重防护原则指 的是设计中应该尽量多设计安全防护, 利用多重防护消耗外界输人的能量, 通过这些防护的损耗, 使建筑结构一直保 持在稳定安全的结构体系, 提高建筑安全能力 ${ }^{[6]}$ 。

尤其是现在的建筑越来越高大, 建筑住户越来越密集, 受到的外界干扰越来越多, 多种防护措施的成本分推后极 低, 为了提高建筑结构的质量, 采用多种防护措施结合提高建筑结构设计的安全性成为了更好的选择。

\section{四、当前建筑结构设计的问题}

(一) 勘查工作形式化

结构设计以工程前期勘查得到的数据为基础, 数据不准确必然导致结构设计不合实际, 进而导致建筑结构的安全 性降低 ${ }^{[7]}$ 。当前很多建筑单位将勘查工作形式化, 存在检测取点随意, 布点疏松, 钻孔深度不达标等诸多问题, 甚至 有些勘查设备在现场闲置, 勘查数据不准, 勘查工作发挥不出应有的作用, 不能提供准确的数据支撑, 影响建筑结构 设计。 


\section{（二）抗震设计标准低}

抗震设计是建筑结构设计的核心环节，是提高建筑安全性的关键。但很多设计单位对抗震性能不够重视。另外， 建筑抗震设计的要求有极大的弹性空间, 且不同抗震设计的成本差距也较大, 规定中也缺乏根据地区情况细化的规 定，这些共同导致建筑抗震设计标准偏低。

(三) 结构耐久性较差

建筑工程大多需要在外界经受风吹日晒, 随着时间变化而老化。老化与损坏是建筑必然面临的问题, 所以建筑有 明确的使用年限。但很多工程结构缺乏维护与保养设计, 进一步加速了建筑结构的老化与损坏, 导致建筑在使用年限 间就出现了结构承载能力明显下降、抗震性能迅速下滑等情况，这些与工程结构设计中忽视耐久因素有直接关系 ${ }^{[8]}$ 。

\section{五、土木工程结构设计安全性改进措施}

\section{(一) 提高对勘查工作的重视}

针对当下工程勘查形式化的问题，施工单位应该提高对勘查工作的重视程度。在勘查过程中制定严格的作业流 程, 加大勘查工程的投人力度, 培养专业勘查人才, 使用现金的勘查技术, 着重提高勘查数据的精准程度, 为后续建 筑结构设计提供详细准确的数据依据 ${ }^{[0]}$ 。

\section{（二）增强工程师的职业素养与安全意识}

建筑的结构设计需要结构工程师施行, 建筑工程师的职业素养与安全意识, 直接影响设计方案的安全性。结构工 程师首先具有完善的专业知识, 主要分为因地制宜和与时俱进, 因地制宜指的是工程师需要结合勘查数据和建筑需 求, 设计科学合理的建筑结构, 与时俱进指的是工程师需要不断学习进步, 更新专业知识, 提高自己的设计水平 ${ }^{[10]}$ 。 其次要具有较高的安全意识, 在结构设计过程中保持认真严谨的工作态度, 认识到自己承担的责任, 能够充分利用自 身的专业技能，设计出完善的建筑结构方案，并积极与施工部门沟通，确保施工正确。

\section{（三）增强建筑结构抗震性能}

在建筑结构设计过程中, 企业应该注重建筑的抗震性能, 不满足于符合国家标准。企业应该对建筑工程所在地的地 质情况与地形特征进行全面勘查, 结合国家相关标准与当地情况选择预期的建筑抗震参数, 据此制定建筑设计目标。在 地震带等特殊区域, 应该适当提高抗震参数, 确保建筑抗震性满足需要, 可以参考地震多发的日本等发达国家的抗震设 计标准，提高结构设计的规范性。此外，遵循建筑结构设计的多重防护原则，结合使用简化平面设计、设置抗震支架、 加强围护结构强度等多种抗震设计, 提高建筑抗震性能 ${ }^{[1]}$ 。需要注意的是, 施工过程中需要注意建筑材料的选择和使 用，确保施工材料符合设计要求，避免材料质量影响抗震设计实用效果。建筑结构抗震设计如下图2所示。

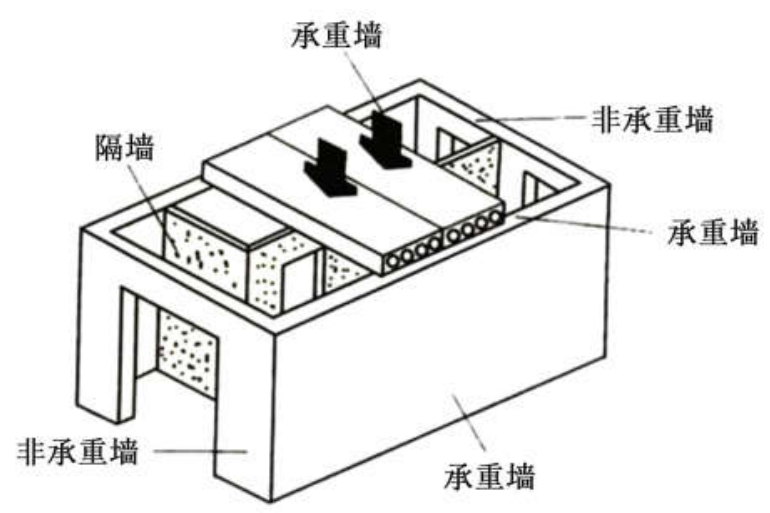

图2 建筑结构抗震设计

（四）重视建筑结构的耐久性

工程结构设计应该注重结构的耐久性，提高建筑结构的使用年限。施工单位可以提高钢筋混凝土等主体材料的耐 久性设计。钢筋混凝土是大多数建筑的主体材料, 其耐久性受到设计、施工、使用和维护的影响, 施工企业可以从设 计与施工方面改良钢筋混凝土构件的耐久性、刚度等性能, 减低影响构件性能的不利因素。施工单位需要了解材料市 场，使用先进的建筑材料，提高结构延性。另外，为了保证建筑的总耐久性，在结构设计时，应该结合建筑结构特点 与外界环境, 适当增加建筑保护层的厚度, 延长老化进程, 从材料、结构和构件三方面人手, 全面提高建筑结构的耐 
久性。

（五）信息技术的引用

随着信息科技的发展, “建筑十互联网” 为提高建筑结构设计的安全性提供了新的途径。以BIM技术为例, 该技 术可以解决以往复杂结构设计难、缺乏模拟途径、方案修改困难等问题, 使用BIM技术不仅可以提高建筑的安全性, 还可以收集处理以往建筑结构设计数据, 帮助企业建立完善的建筑结构设计体制, 提高之后建筑解结构设计的质量与 效率。

\section{六、结束语}

总而言之, 提高建筑结构设计的安全性对建筑行业的发展具有重要意义, 但当前的结构设计存在勘查数据不准、 抗震设计标准低和耐久性差等问题, 建筑工程企业需要, 坚持 “安全第一, 质量第一” 的设计理念, 加强对结构设计 安全性的重视，结合项目情况针对性地制定改正措施，确保建筑结构安全。

\section{参考文献:}

[1]杨光泽.浅谈油田土木工程结构设计中的安全性和经济性[J].中国石油和化工标准与质量, 2021,41(03):114-116.

[2]焦怡彬,梁俪馨.加强土木工程结构设计安全性的措施讨论[J].居舍, 2021(02):77-78.

[3]陈松庭.探微土木工程结构设计中的安全性与经济性[J].中华建设, 2020(09):106-107.

[4]金根.土木工程结构设计中的安全性与经济性[J].中国高新科技, 2020(16):43-44+100.

[5]李星.浅谈土木工程结构设计中的安全性与经济性[J].建材与装饰, 2020(11):72-73.

[6]周金金,杜于熙,郑龙龙, 曹乐乐.土木工程结构设计中的安全性与经济性探讨[J]. 科技经济导刊, 2020,28(10):37+24.

[7]叶昕.基于安全性及经济价值前提的土木工程结构设计与地基加固技术探究[J]. 花炮科技与市场, 2019(04):122.

[8]吕洪海.基于经济发展下土木工程结构设计中的安全性与经济性探讨[J].门窗, 2019(18):124+126.

[9]张波.土木工程结构安全性评估、健康监测及诊断研究[J].城市建设理论研究(电子版), 2019(18):30.

[10]云生翔.浅谈土木工程结构设计中实现安全性与经济性措施[J].中外企业家, 2018(34):134.

[11] 侯伟.提高土木工程结构设计中的安全性及经济性的方法分析[J].绿色环保建材, 2018(10):64-65. 